\title{
Effects of Staurosporine on Exocytosis and Endocytosis at Frog Motor Nerve Terminals
}

\author{
Ute Becherer, Cristina Guatimosim, and William J. Betz \\ Department of Physiology and Biophysics, University of Colorado Medical School, Denver, Colorado 80262
}

\begin{abstract}
Observations of the dynamic staining and destaining of FM1-43 in frog motor nerve terminals (Henkel and Betz, 1995) suggested that staurosporine might shorten the interval between exocytosis and endocytosis, inducing a "kiss and run" mode of exocytosis and endocytosis. We tested this hypothesis by using FM1-43 imaging (to measure the time course of FM1-43 endocytosis), intracellular recording of evoked synaptic potentials (to measure acetylcholine release), and electron microscopy (to examine synaptic vesicle distribution). Staurosporine reduced FM1-43 uptake during but not after a tetanus, in-
\end{abstract}

creased the speed of end plate potential (EPP) amplitude rundown, and greatly slowed the recovery from synaptic depression. Ultrastructural observations showed pronounced vesicle depletion near active zones after tetanic stimulation in staurosporine-treated preparations. These results suggest that staurosporine acted primarily to impair mobilization of synaptic vesicles during tetanic stimulation.

Key words: staurosporine; exocytosis; endocytosis; synaptic vesicles; frog neuromuscular junction; FM1-43
The synaptic vesicle cycle comprises three major steps: exocytosis, endocytosis, and intracellular trafficking. The mechanisms of exocytosis and endocytosis have been studied extensively at a molecular level (for review, see Scheller, 1995; Augustine et al., 1996; DeCamilli and Takei, 1996; Mellman, 1996) and at a kinetic level (Steyer and Almers, 1999). Relatively less is known of the trafficking of synaptic vesicles, both inside the cell and outside, during the interval between opening of the fusion pore and closing of the fission pore. Intense stimulation causes vesicles to collapse into the surface membrane and to be recovered by a clathrin-mediated process (Heuser and Reese, 1973, 1977). An alternative route involving direct closure of the fusion pore ("kiss and run" exocytosis) has been demonstrated in neuroendocrine cells (Chow et al., 1992; Alvarez de Toledo et al., 1993; Ales et al., 1999) (for review, see Artalejo et al., 1998), but direct evidence for such a mechanism at synapses is lacking, although considerable indirect evidence is consistent with such a model. For example, synaptic vesicles retain their identity through the exo- and endocytic cycle (Murthy and Stevens, 1998), and endocytosis in retinal bipolar cells is faster than other clathrin-mediated endocytic processes (von Gersdorf and Matthews, 1994); the kinase inhibitor staurosporine was reported to inhibit FM1-43 release more than acetylcholine $(\mathrm{ACh})$ release during repetitive stimulation (Henkel and Betz, 1995) and also to shorten the apparent interval between exo- and endocytosis (Klingauf et al., 1998).

\footnotetext{
Received June 30, 2000; revised Nov. 9, 2000; accepted Nov. 9, 2000.

This work was supported by research grants from Muscular Dystrophy Association and National Institutes of Health and a Companha de Aperfei $\div$ oamento de Pessoal de N 205 vel Superior fellowship to C.G. We thank Steve Fadul for his expert and enduring assistance and Dot Dill for her excellent help in electron microscopy.

Correspondence should be addressed to Dr. W. J. Betz, Department of Physiology and Biophysics, University of Colorado Medical School, Campus Box C-240, Denver, CO 80262. E-mail: Bill.Betz@UCHSC.edu.

Dr. Becherer's present address: Max Planck Institute for Experimental Medicine, Abt. für Molekulare Biologie Neuronaler Signale, Hermann-Rein-Strasse 3, D-37075 Göttingen, Germany. E-mail: ubecher@gwdg.de.

Dr. Guatimosim's present address: Departamento de Farmacologia, Instituto Ciências Biológicas, Universidade Federal de Minas Gerais, Avenida Antonio Carlos 6627, 31270-901, Belo Horizonte MG, Brazil. E-mail: cguati@icb.ufmg.br. Copyright (C) 2001 Society for Neuroscience $0270-6474 / 01 / 210782-06 \$ 15.00 / 0$
}

Kraszewski et al. (1996) concluded that the effects of staurosporine in hippocampal cultures reflected a reduction of vesicle mobility (as also observed by Henkel and Betz, 1995), without revealing evidence of a kiss and run mechanism.

The aim of the present work was to reexamine the hypothesis that staurosporine increased the speed of endocytosis at the frog neuromuscular junction. We used optical methods based on styryl dye FM1-43 to measure the rate of endocytosis (Wu and Betz, 1996) and electrophysiological methods to measure ACh release and to assess the depletion and replenishment of the readily releasable pool of vesicle. Electron microscopy (EM) was used to assess the effect of staurosporine on the distribution of vesicles within the nerve terminals. Our results suggest that the primary effect of staurosporine is not to change the speed of endocytosis but to reduce the mobilization of vesicles during tetanic stimulation.

\section{MATERIALS AND METHODS}

Most methods have been described previously (Betz et al., 1992; Betz and Bewick, 1992, 1993). Frog (Rana pipiens) cutaneous pectoris nervemuscle preparations were dissected and mounted in a Sylgard-lined chamber containing normal frog Ringer's solution [containing (in mM) $115 \mathrm{NaCl}, 2 \mathrm{KCl}, 1.8 \mathrm{CaCl}_{2}$, and $5 \mathrm{HEPES}$. Then the preparation was incubated with $2 \mu \mathrm{M}$ staurosporine for $1 \mathrm{hr}$; the contralateral nervemuscle preparation served as a control. The muscle nerve was drawn into a suction electrode for electrical stimulation.

For the recording of end plate potentials (EPPs), curare $(2 \mathrm{mg} / \mathrm{ml})$ or $\mu$-conotoxin $(16 \mu \mathrm{M})$ was added to the bath solution to reduce contraction of the muscle. Although movements could be stopped completely with curare, the blockade of postsynaptic receptors reduced spontaneous miniature EPPs (mEPPS) and sometimes evoked EPPs to undetectable levels. The use of $\mu$-conotoxin avoided this difficulty, and although movements sometimes dislodged the recording electrode, usually impalements were stable during stimulation. Recordings were rejected if the membrane potential became less negative than $-60 \mathrm{mV}$ or changed by $>30 \mathrm{mV}$. Micropipettes (15-23 M 2 ) for intracellular recording were filled with $3 \mathrm{~m}$ potassium acetate. To obtain recordings of mEPPs not obscured by action potentials during a tetanus, we interrupted electrical stimulation of the preparation for 1-2 sec every $10 \mathrm{sec}$, during which time $\mathrm{mEPP}$ recordings were obtained. Error bars show \pm SEM.

Fluorescence images of selected surface terminals were viewed with a 
A a

Protocol :

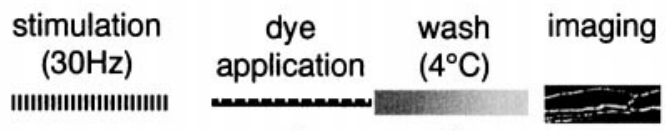

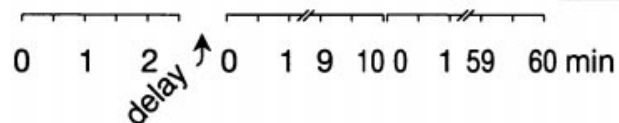

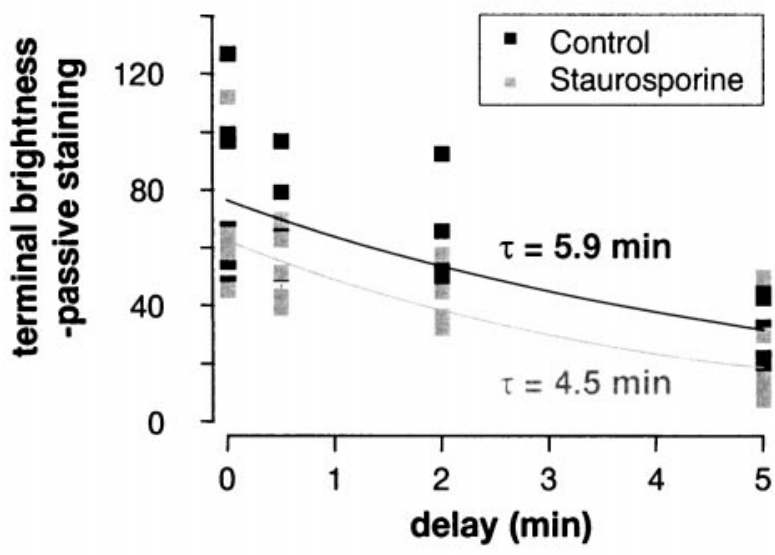

B

a

Protocol :
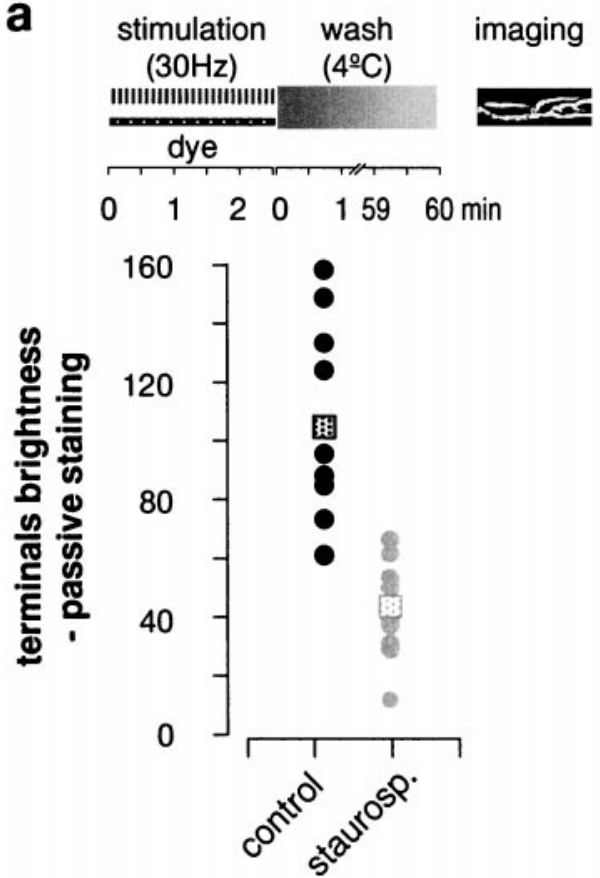

Nikon upright epifluorescence microscope equipped with a Zeiss $40 \times$ water immersion ( 0.75 numerical aperture) objective lens, a $100 \mathrm{~W} \mathrm{Hg}$ lamp, $6.25-25 \%$ neutral density transmission filters, a 480/30 nm bandpass excitation filter, and a 535/40 nm bandpass emission filter. Images were acquired with Inovision software (Chapel Hill, NC) and processed with G. W. Hannaway software (Boulder, CO) running on a Silicon Graphics $\mathrm{O} 2$ computer.

To measure the endocytic time course after a tetanus, we used the method described by Wu and Betz (1996), adapted from a method first introduced by Ryan et al. (1993). Nerve terminals were stimulated for 2.5 $\min$ at $30 \mathrm{~Hz}$ in normal Ringer's solution. After an additional delay time (0-5 min), FM1-43 (4.3 $\mu \mathrm{M})$ was added to the bath solution. The dye incubation time was $10 \mathrm{~min}$, sufficient to permit complete endocytosis. b
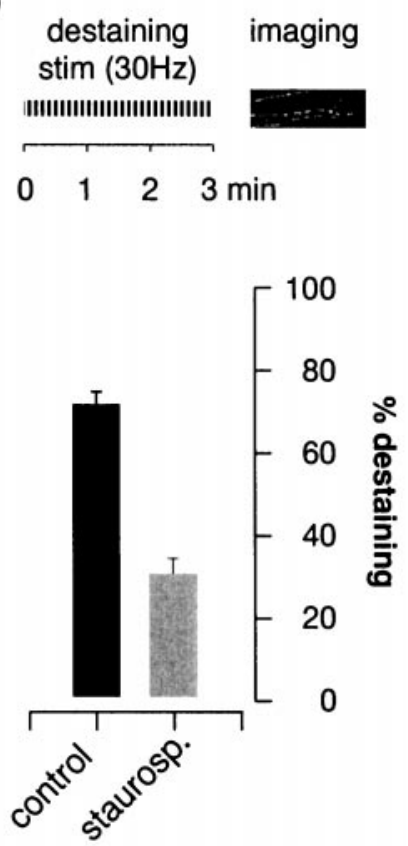

Figure 1. Staurosporine reduced FM1-43 uptake during, but not after, tetanic stimulation. Experimental protocols are shown above each panel. $A$, FM1-43 uptake after a tetanus. Preparations were stimulated $2.5 \mathrm{~min}$ at 30 $\mathrm{Hz}$, and dye was applied after a variable delay (x-axis) for $10 \mathrm{~min}$ and then washed away. $a$, Average fluorescence of terminals after stimulation in control (black squares) and in staurosporinetreated preparations (gray squares). Each symbol shows the mean fluorescence of four to six terminals in one muscle. Exponential fits gave endocytic time constants of $4.5 \mathrm{~min}$ (Control) and 5.9 min (Staurosporine). $b$, After the experiment the terminals were destained (also $30 \mathrm{~Hz}$ for $2.5 \mathrm{~min}$ ). Control terminals lost $\sim 2.5$ times more dye than did staurosporine-treated terminals. $B$, Uptake of FM1-43 during tetanic stimulation. Preparations were stimulated in the presence of dye and then quickly washed. $a$, Controls took up $\sim 2.5$ times more dye than did staurosporinetreated terminals $(p<0.01 ; n=9)$. Each circle shows the mean of four to six terminals in a muscle; squares mark mean values. $b$, Destaining was reduced only slightly by staurosporine treatment. Error bars show \pm SEM.
Then the preparation was washed for $\sim 1 \mathrm{hr}$ in $4^{\circ} \mathrm{C}$ Ringer's solution and finally was imaged. For each delay time, four to six treated and control preparations were subjected to the same process, and in each preparation four to six surface terminals were selected for quantification of fluorescence intensity.

To assess the amount of endocytosis taking place during a tetanus, we added FM1-43 $(4.3 \mu \mathrm{M})$ before stimulation $(30 \mathrm{~Hz}$ for $5 \mathrm{~min})$ and removed it immediately after by pouring off the dye-containing solution and plunging the preparation into ice-cold Ringer's solution. In some cases $\mathrm{Ca}^{2+}$ in the Ringer's solution was exchanged for $\mathrm{Cd}^{2+}$ to stop all residual exocytosis, thereby ensuring that the dye that was taken up was attributable to exocytosis that occurred during stimulation. Because no difference could be detected between the two washing conditions $\left(\mathrm{Ca}^{2+}\right.$ 


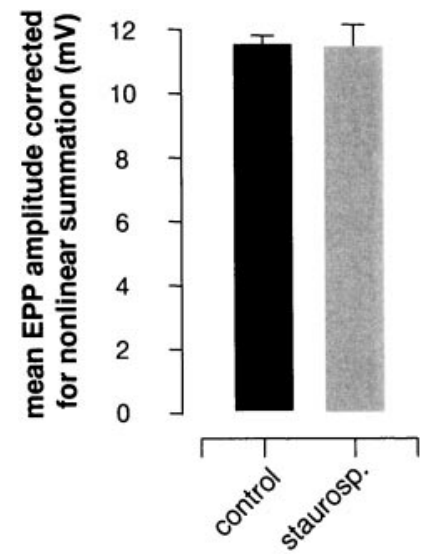

Figure 2. Staurosporine did not change the amplitude of EPPs evoked by low frequency stimulation $(0.06 \mathrm{~Hz})$. EPPs recorded in blind experiments were not altered significantly by staurosporine treatment $(p>0.5$; four to six cells in each of five preparations per condition). Error bars show \pm SEM.

containing Ringer's solution or $\mathrm{Cd}^{2+}$ containing solution), results obtained under both conditions were pooled. In each preparation $(n=9$ controls and 9 staurosporine-treated) four to six surface terminals were imaged. The same terminals were reimaged after destaining $(30 \mathrm{~Hz}$ for $3 \mathrm{~min})$.

For image analysis the part of the selected terminals in best focus was outlined automatically, and the mean fluorescence intensity of the pixels in the outline was calculated. The same outline was used to measure fluorescence after destaining. Fluorescence values were corrected by subtracting the mean fluorescence intensity of terminals that were stained passively (exposed to FM1-43 for 2.5 min without nerve stimulation). For preparations that were stained after stimulation, the duration of passive dye exposure was $10 \mathrm{~min}$.

For ultrastructural studies, eight muscles (four control and four pretreated with staurosporine) from four frogs were stimulated (2.5 min at $30 \mathrm{~Hz}$ ) by the nerve. After a $20 \mathrm{~min}$ rest the preparations were fixed in ice-cold fixative solution (1.6\% paraformaldehyde and $2.0 \%$ glutaraldehyde at $4^{\circ} \mathrm{C}$ ) for $30 \mathrm{~min}$. After washing with phosphate buffer (PB; $\left.0.1 \mathrm{M}\right)$, each muscle was cut into four pieces, postfixed in osmium ( $2 \%$ osmium in $0.1 \mathrm{M} \mathrm{PB}$ ) at $4^{\circ} \mathrm{C}$, and dehydrated through an ascending series of ethanol solutions. After dehydration the muscles were stained en bloc with uranyl acetate (4\% uranyl acetate in 50\% ethanol) and embedded in EPON. The blocks were sectioned, and gray-gold sections $(80-90 \mathrm{~nm})$ were collected and viewed with a Philips CM10 electron microscope. Only nerve terminals that contained typical active zones, identified by the openings of postsynaptic folds, were considered for analysis.

Staurosporine (Sigma, St. Louis, MO) was dissolved in $1 \mathrm{~mm}$ DMSO; $\mu$-conotoxin GIIIA (Bachem, Torrance, CA) was dissolved in water (5 $\mathrm{mM}$ ), aliquoted, and stored at $-20^{\circ} \mathrm{C}$. Curare (D-turbocurarine- $\mathrm{Cl}$; Sigma) was dissolved in water $(1.5 \mathrm{~mm})$, as was FM1-43 (1.6 mM; Molecular Probes, Eugene, OR), and kept at $4^{\circ} \mathrm{C}$. The salts used for the Ringer's solution were from Sigma.

\section{RESULTS}

To measure the effect of staurosporine on endocytosis, we used a method developed by Ryan and colleagues (1993, 1996) and applied to the frog neuromuscular junction by $\mathrm{Wu}$ and Betz (1996). As illustrated in Figure $1 A a$, the muscle nerve was stimulated for $2.5 \mathrm{~min}$ at $30 \mathrm{~Hz}$ in the absence of dye. After a variable delay FM1-43 was added for $10 \mathrm{~min}$. Then after extensive washing, four to six surface motor nerve terminals were imaged. As illustrated in Figure $1 A a$, control dye uptake decayed with a time constant of $5.9 \mathrm{~min}$ (cf. Wu and Betz, 1996). Staurosporine had little effect on the amount or time course (time constant, $4.5 \mathrm{~min}$ ) of post-tetanic dye uptake by the terminals. To test whether the staurosporine was active, we subsequently destained each preparation. Treatment with staurosporine reduced destaining by $58 \%$

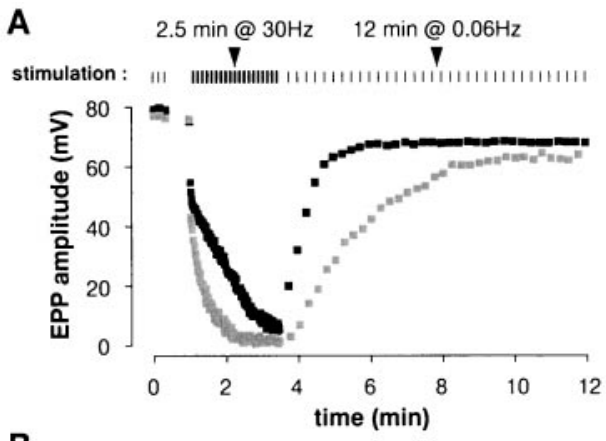

B
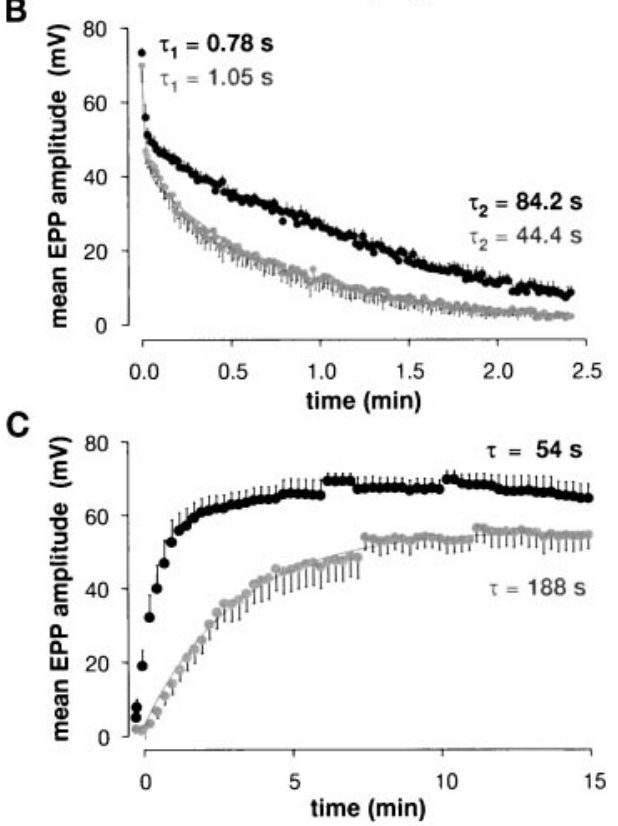

Figure 3. EPPs during and after tetanic stimulation were reduced significantly by staurosporine. $A$, Results from a typical experiment (protocol illustrated at top). During the $30 \mathrm{~Hz}$ train, EPP rundown was faster and recovery was slower at staurosporine-treated end plates (gray symbols) than in controls (black symbols). B, EPP rundown during tetanic stimulation. Shown are averages from five cells per condition. Double exponential fits gave time constants as shown on the graph; the main effect of staurosporine was to slow the second component by a factor of $\sim 2$. $C$, EPP recovery after the tetanus (five cells per condition). The data are fit well with single exponentials; staurosporine slowed recovery by $\sim 3.5$-fold.

(Fig. 1Ab). We concluded that the endocytic rate after the end of tetanic stimulation is not affected by staurosporine.

We also examined the effect of staurosporine on endocytosis during a tetanus, because endocytosis has been reported to be accelerated by the elevation in intracellular calcium ion concentration that accompanies tetanic stimulation (Klingauf et al., 1998; Ales et al., 1999). The protocol (Fig. 1Ba) consisted of stimulating the preparation for $2.5 \mathrm{~min}$ at $30 \mathrm{~Hz}$ with dye in the bath. The dye was washed out immediately after the end of stimulation with ice-cold normal frog Ringer's. In four of nine experiments $1 \mathrm{mM} \mathrm{Cd}^{2+}$ was added to the washing medium to reduce further any residual exocytosis; this addition had no significant effect on results, which were pooled. Staurosporine treatment reduced dye uptake during the tetanus to $\sim 40 \%$ of control levels $(p<0.01)$.

Henkel and Betz (1995) detected no effect of staurosporine on evoked muscle action potentials and synaptic potentials sampled either at rest or during $10 \mathrm{~Hz}$ stimulation and concluded that 


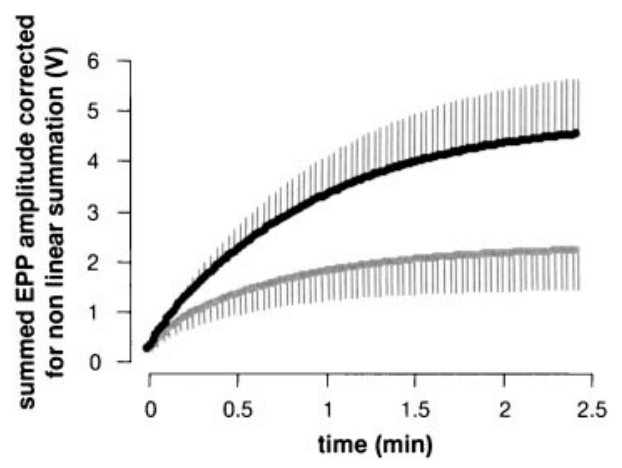

Figure 4. Total release during a tetanus was reduced by staurosporine. Mean EPP amplitudes (see Fig. 3) during tetanic stimulation were corrected for nonlinear voltage summation and summed $(n=5)$. Staurosporine reduced total release over the 2.5 min train by a factor of $\sim 2$.

exocytosis was not affected by staurosporine. However, because of their sampling procedure (single fibers were not followed over time) and a large amount of scatter in their data, we decided to reexamine transmitter release after staurosporine exposure. We used $\mu$-conotoxin to block muscle fiber action potentials, which enabled us to maintain penetrations indefinitely during repetitive stimulation without blocking postsynaptic receptors (Zengel and Sosa, 1994). Experiments were performed blind. In resting preparations EPP amplitudes were not affected by staurosporine treatment (Fig. 2), in agreement with the results of Henkel and Betz (1995). However, as illustrated by the typical result in Figure $3 A$, during $30 \mathrm{~Hz}$ stimulation EPP rundown was noticeably faster in the staurosporine-treated preparation and EPP recovery after the tetanus was slowed profoundly, as compared with the contralateral control. Results from all experiments are summarized in Figure $3 B$ (EPP rundown) and Figure $3 C$ (post-tetanic EPP recovery). EPP rundowns were well fit by double exponentials; the main effect of staurosporine treatment was to prolong the time course of the slow component of rundown (from 44 to $84 \mathrm{sec}$; $p<0.02$; cf. Henkel and Betz, 1995). This, of course, suggests that total transmitter release during the tetanus was reduced by staurosporine treatment. EPP recovery after the tetanus (Fig. 3C) was fit reasonably well with single exponentials; the effect of staurosporine was to slow the recovery time constant more than threefold, from 54 to $188 \mathrm{sec}$.

Figure 4 shows the cumulative sum of evoked EPPs during the tetanus (from Fig. 3B), corrected for nonlinear summation (Martin, 1955). Total transmitter release was reduced approximately twofold by staurosporine treatment, in reasonable agreement with the observed 2.5-fold reduction in dye uptake (see Fig. $1 B a$ ). To test for the possibility that staurosporine caused postsynaptic receptor desensitization, we recorded spontaneous miniature EPPs (mEPPs) during tetanic stimulation. As illustrated in Figure $5 A$, the $30 \mathrm{~Hz}$ tetanus was interrupted every $10 \mathrm{sec}$ for $\sim 800 \mathrm{msec}$, during which time mEPPs were recorded. mEPP amplitudes were not affected significantly by staurosporine treatment ( $n=9$ control and contralateral staurosporine-treated preparations) either before, during, or after the tetanus $(30 \mathrm{~Hz}$ for $1 \mathrm{~min})$. mEPP frequency, however, was reduced significantly by staurosporine (Fig. 5B), in agreement with the results of Henkel and Betz (1995).

In summary, staurosporine reduced evoked transmitter release, but only during high frequency stimulation. It is during this time that the nerve terminal must mobilize vesicles from the reserve
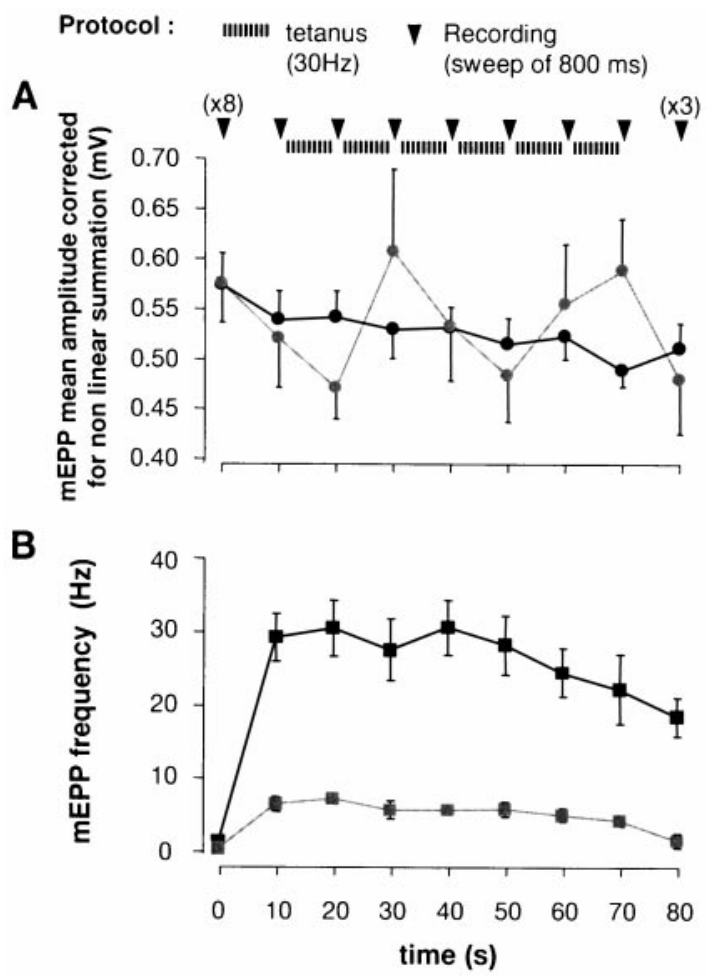

Figure 5. Staurosporine reduced the frequency, but not the amplitude, of spontaneous mEPPs. $A$, As illustrated at the top, $30 \mathrm{~Hz}$ stimulation was interrupted every $10 \mathrm{sec}$ for $\sim 1 \mathrm{sec}$, during which time mEPPs could be recorded free of interference from action potentials. $a$, mEPP amplitude. In controls (black) mEPP amplitude decreased by less than $\sim 10 \%$ during the tetanus; staurosporine ( gray) evidently did not alter this significantly. $B$, mEPP frequency. Staurosporine treatment (gray) reduced $\mathrm{mEPP}$ frequency overall (from 1.3 to $0.5 \mathrm{~Hz}$ at rest and from 27.5 to $5.7 \mathrm{~Hz}$ during tetanic stimulation). Error bars show \pm SEM.

pool to replenish the depleted readily releasable pool. This naturally suggests that staurosporine may interfere with vesicle mobilization (cf. Henkel and Betz, 1995; Kraszewski et al., 1996). To study this possibility further, we examined the ultrastructure of nerve terminals fixed immediately after tetanic stimulation (2.5 min at $30 \mathrm{~Hz}$; Fig. 6). We focused particular attention on the region near active zones, which were identified by adjacent openings of postsynaptic folds. In a control preparation (Fig. 6 $A$ ) vesicles were observed throughout the region flanking the active zone [semicircles mark distances of $200 \mathrm{~nm}$ (dashed line) and 600 $\mathrm{nm}$ (solid line) from the active zone]. Staurosporine treatment did not alter significantly the total number of synaptic vesicles in terminal profiles (results not shown) but led to a selective depletion of vesicles in the immediate vicinity of the active zone (Fig. $6 B)$. Results were quantified by digitizing images and marking active zones and synaptic vesicles. Figure $6 C$ shows that staurosporine treatment caused a profound depletion of vesicles within $\sim 200 \mathrm{~nm}$ of active zones. Such depletion was not observed in resting terminals treated with staurosporine (Henkel and Betz, 1995) and thus must result from tetanic stimulation, providing further evidence that staurosporine inhibited vesicle mobilization.

\section{DISCUSSION}

The present work confirms some, but not all, of the previous observations of the effects of staurosporine on synaptic vesicle 

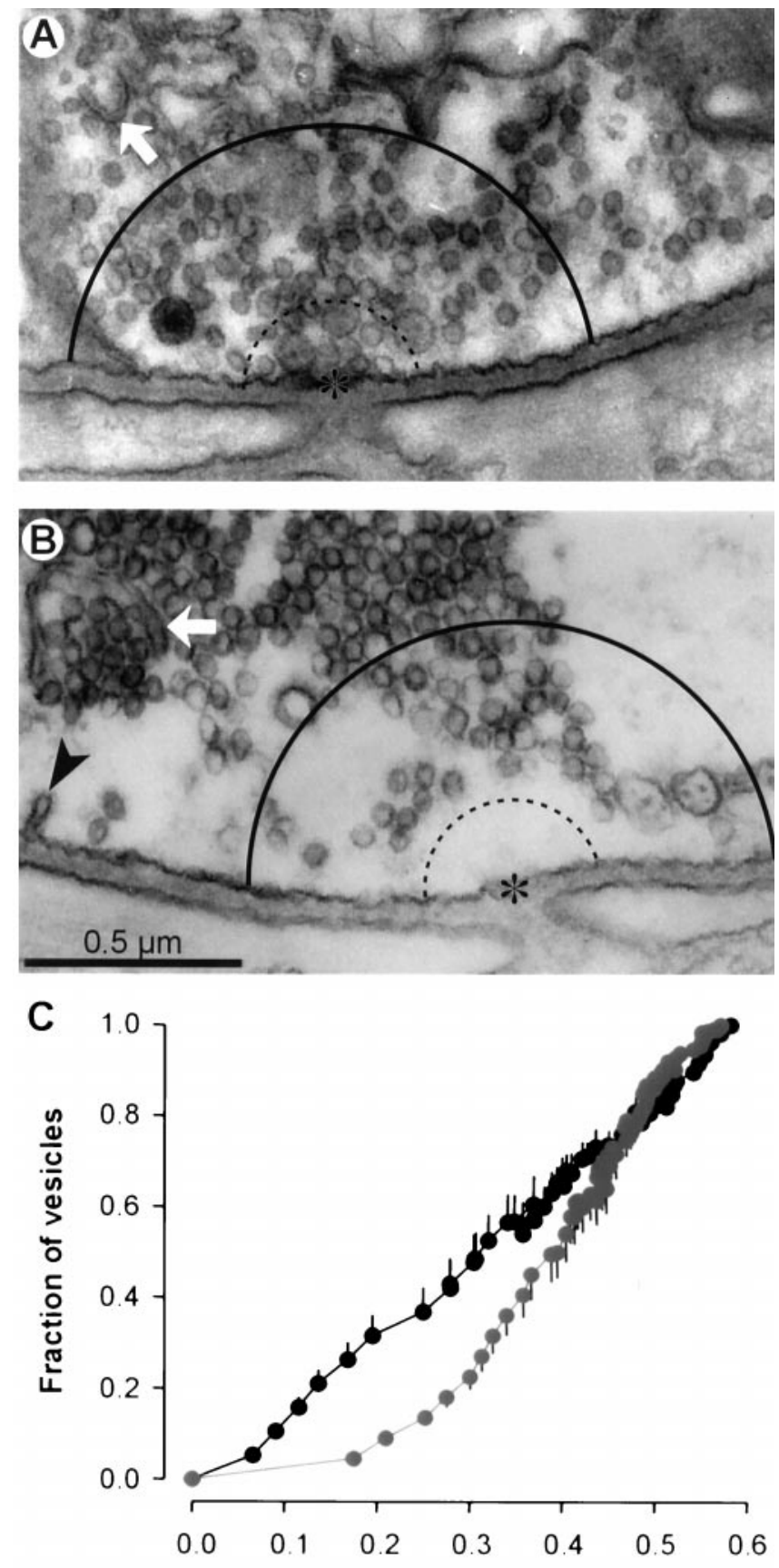

Distance from the active zone $(\mu \mathrm{m})$

Figure 6. Staurosporine caused vesicle depletion near active zones after tetanic stimulation. Preparations were fixed immediately after stimulation ( $30 \mathrm{~Hz}$ for $2.5 \mathrm{~min}$ ) and prepared for electron microscopy. Active zones (asterisks) were identified by adjacency to openings of postsynaptic folds. Vesicles in control $(A)$ and staurosporine-treated $(B)$ terminals lying within $0.6 \mu \mathrm{m}$ (solid curved line; dotted line shows $0.2 \mu \mathrm{m}$ distance) were counted, and distances to the nearest active zone were measured. Cisternae (arrow) and coated pits (arrowhead) often were observed. $C$, The average fraction of vesicles ( $n=16$ terminals) located within a given distance from the active zone reveals a depletion of vesicles near active zones in staurosporine-treated terminals (gray) as compared with controls (black). Error bars show \pm SEM.

recycling in frog motor nerve terminals and adds new information. All together, the results from FM1-43 imaging, electrophysiological recordings, and EM observations are explained most simply by a mechanism in which staurosporine interferes with the mobility of synaptic vesicles within the nerve terminal during tetanic stimulation. Thus we showed that staurosporine increases the speed of EPP amplitude rundown during a tetanus, thereby reducing quantal release and resulting in a reduction of the endocytic uptake of FM1-43 by the nerve terminal. The posttetanic depletion of synaptic vesicles in the vicinity of exocytic active zones observed by electron microscopy is consistent with these observations. In addition, staurosporine greatly slowed the recovery of EPP amplitudes from depression after tetanic stimulation. This last effect also has been demonstrated in snake motor nerve terminals treated with the actin-disrupting agent latrunculin A (Cole et al., 2000). It is curious that the amount of posttetanic uptake of FM1-43 was unchanged by staurosporine (see Fig. $1 \mathrm{Aa}$ ), although transmitter secretion was greatly reduced (see Fig. 4). The complexity of post-tetanic endocytosis in frog motor nerve terminals recently revealed by the differential effects of FM1-43 and FM2-10 (Richards et al., 2000) makes this a subject for further study.

All of these results can be explained by an inhibition of mobilization of synaptic vesicles from a reserve pool to a readily releasable pool. The main difference between the present results and those of Henkel and Betz (1995) is the demonstration here that staurosporine reduces quantal release during a tetanus (by a factor of $\sim 2$ ). In the earlier work EPPs were sampled by impaling many muscle fibers sequentially during tetanic stimulation, and the large scatter in the resulting data obscured the inhibition in release. In the present work we recorded EPPs from a single cell throughout each experiment, a protocol permitted by using $\mu$-conotoxin to reduce muscle contractions without reducing postsynaptic sensitivity to the transmitter. Henkel and Betz (1995) also reported that staurosporine arrested the normal movements of organelles, such as Schwann cell endosomes; that it inhibited the vesicle-mobilizing effect of okadaic acid, which disrupts clusters of synaptic vesicles (Betz and Henkel, 1994); and that it blocked ultrastructural changes because of prolonged nerve stimulation. These findings further support the hypothesis that the main effect of staurosporine was to reduce the movement of vesicles within the nerve terminal.

The effects of staurosporine have been studied in other preparations. In cultured hippocampal neurons Kraszewski et al. (1996) showed that staurosporine blocked by $70 \%$ the release of FM1-43 and that it also blocked synaptic vesicle intermixing as measured by fluorescence recovery after photobleaching. Moreover, staurosporine did not interfere with endocytic uptake of an antibody to the lumenal domain of synaptotagmin. The unaltered uptake of these large molecules argues against the possibility that staurosporine induced kiss and run exo- and endocytosis and further supports the idea that staurosporine reduced the mobility of clathrin-coated vesicles and endosomal intermediates, enhancing the probability of local recycling. Klingauf et al. (1998) measured the time course of endocytosis in hippocampal neurons. They showed that in these cells endocytosis evidently proceeded at two rates, depending on the stimulation paradigm. The effect of staurosporine was to reduce the initial release of FM1-43 during stimulation with high potassium-containing medium. The authors attributed the effect of staurosporine to an acceleration of the fast mode of endocytosis from $\sim 6$ to $\sim 1.7 \mathrm{sec}$. In chromaffin cells, cell-attached capacitance monitoring has revealed that plasma membrane is renewed via constitutive exo- and endocytosis of small vesicles (Henkel et al. 2000). Some of these events are transient and produce capacitance flickers repeatedly and 
regularly for periods lasting 5-10 sec. The occurrence of these rhythmic bursts was enhanced greatly by staurosporine, suggesting that staurosporine promoted a kiss and run process in chromaffin cells. However, detailed analysis suggested that the events reflected the halting pitching from endosomes rather than fusion pore formation and thus were probably not secretory. Stevens and Sullivan (1998) showed that in cultured hippocampal neurons the protein kinase C (PKC) activator phorbol-12-myristate 13acetate (PMA) increased the size of the readily releasable pool and accelerated the refilling of empty docking sites. PKC has been shown to have similar effects on the recruitment of secretory granules to the readily releasable pool in chromaffin cells (Gillis et al., 1996; Smith et al., 1998). Finally, Ryan (1999) showed that the myosin light chain kinase (MLCK) inhibitors ML9 or BDM partially blocked FM1-43 destaining of cultured hippocampal neurons without altering the time course of endocytosis, consistent with the notion of an MLCK-mediated vesicle mobilization mechanism. In summary, there appear to be at least two protein kinases, MLCK and PKC, involved in synaptic vesicle transport at nerve terminals. Because staurosporine inhibits a wide spectrum of protein kinase, it may act via either or both of these pathways.

\section{REFERENCES}

Ales E, Tabares L, Poyato JM, Valero V, Lindau M, Alvarez de Toledo G (1999) High calcium concentrations shift the mode of exocytosis to the kiss-and-run mechanism. Nat Cell Biol 1:40-44.

Alvarez de Toledo G, Fernandez-Chacon R, Fernandez JM (1993) Release of secretory products during transient vesicle fusion. Nature 363:554-558

Artalejo CR, Elhamdani A, Palfrey HC (1998) Secretion: dense-core vesicles can kiss-and-run too. Curr Biol 8:R62-R65.

Augustine GJ, Burns ME, DeBello WM, Pettit DL, Schweizer FE (1996) Exocytosis: proteins and perturbations. Annu Rev Pharmacol Toxicol 136:659-701.

Betz WJ, Bewick GS (1992) Optical analysis of synaptic vesicle recycling at the frog neuromuscular junction. Science 255:200-203.

Betz WJ, Bewick GS (1993) Optical monitoring of transmitter release and synaptic vesicle recycling at the frog neuromuscular junction. J Physiol (Lond) 460:287-309.

Betz WJ, Henkel AW (1994) Okadaic acid disrupts clusters of synaptic vesicles in frog motor nerve terminals. J Cell Biol 124:843-854.

Betz WJ, Mao F, Bewick GS (1992) Activity-dependent fluorescent staining and destaining of living vertebrate motor nerve terminals. J Neurosci 12:363-375.

Chow RH, von Ruden L, Neher E (1992) Delay in vesicle fusion revealed by electrochemical monitoring of single secretory events in adrenal chromaffin cells. Nature 356:60-63.

Cole JC, Villa BR, Wilkinson RS (2000) Disruption of actin impedes transmitter release in snake motor terminals. J Physiol (Lond) 525:579-586.
DeCamilli P, Takei K (1996) Molecular mechanisms in synaptic vesicle endocytosis and recycling. Neuron 16:481-486.

Gillis KD, Mossner R, Neher E (1996) Protein kinase C enhances exocytosis from chromaffin cells by increasing the size of the readily releasable pool of secretory granules. Neuron 16:1209-1220.

Henkel A, Betz WJ (1995) Staurosporine blocks evoked release of FM1-43 but not acetylcholine from frog motor nerve terminal. J Neurosci 15:8246-8256.

Henkel AW, Meiri H, Horstmann H, Lindau M, Almers W (2000) Rhythmic opening and closing of vesicles during constitutive exo- and endocytosis in chromaffin cells. EMBO J 19:84-93.

Heuser JE, Reese TS (1973) Evidence for recycling of synaptic vesicle membrane during transmitter release at the frog neuromuscular junction. J Cell Biol 57:315-344.

Heuser JE, Reese TS (1977) Structure of the synapse. In: Handbook of physiology, Vol 1, The nervous system, Chap 8, pp 261-294. Bethesda, MD: American Physiological Society.

Klingauf J, Kavalali ET, Tsien RW (1998) Kinetics and regulation of fast endocytosis at hippocampal synapses. Nature 394:581-585.

Kraszewski K, Daniell L, Mundigl O, DeCamilli P (1996) Mobility of synaptic vesicles in nerve endings monitored by recovery from photobleaching of synaptic vesicle-associated fluorescence. J Neurosci 16:5905-5913.

Martin AR (1955) A further study of the statistical composition of the end-plate potential. J Physiol (Lond) 130:114-122.

Mellman I (1996) Endocytosis and molecular sorting. Annu Rev Cell Dev Biol 12:575-625.

Murthy VN, Stevens CF (1998) Synaptic vesicles retain their identity through the endocytic cycle. Nature 392:497-501.

Richards DA, Guatimosim C, Betz WJ (2000) Two endocytic recycling routes fill two vesicle pools in frog motor nerve terminals. Neuron 27:551-559.

Ryan TA (1999) Inhibitors of myosin light chain kinase block synaptic vesicle pool mobilization during action potential firing. J Neurosci 19:1317-1323.

Ryan TA, Reuter H, Wendland B, Schweizer FE, Tsien RW, Smith SJ (1993) The kinetics of synaptic vesicle recycling measured at single presynaptic boutons. Neuron 11:713-724.

Ryan TA, Smith SJ, Reuter H (1996) The timing of synaptic vesicle endocytosis. Proc Natl Acad Sci USA 93:5567-5571.

Scheller RH (1995) Membrane trafficking in the presynaptic nerve terminal. Neuron 14:893-897.

Smith C, Moser T, Xu T, Neher E (1998) Cytosolic $\mathrm{Ca}^{2+}$ acts by two separate pathways to modulate the supply of release-competent vesicles in chromaffin cells. Neuron 20:1243-1253.

Stevens CF, Sullivan JM (1998) Regulation of the readily releasable vesicle pool by protein kinase C. Neuron 21:885-893.

Steyer JA, Almers W (1999) Tracking single secretory granules in live chromaffin cells by evanescent-field fluorescence microscopy. Biophys $\mathbf{J}$ 76:2262-2271.

von Gersdorf H, Matthews G (1994) Dynamics of synaptic vesicle fusion and membrane retrieval in synaptic terminals. Nature 370:652-655.

Wu LG, Betz WJ (1996) Nerve activity, but not intracellular calcium, determines the time course of endocytosis at the frog neuromuscular junction. Neuron 17:769-779.

Zengel JE, Sosa MA (1994) Changes in MEEP frequency during depression of evoked release at the frog neuromuscular junction. J Physiol (Lond) 477:267-277. 